\title{
On the Characteristics of Discharges from Electrostatically Charged Cloths
}

\author{
Tadashi Hirakawa* \\ Central Research Institute, Teijin Limited, Hino, Tokyo 191, Japan.
}

(Received June 14, 1974)

\begin{abstract}
Generation of static charge by friction, discharges in the course of separation from a backing metallic plate, and discharges to an approaching sphere or wire electrodes after such a separation were investigated for various cloths. In the separation procedure, a large proportion of charge was lost through discharges to the backing plate, giving a maximum charge density of about $15 \mu \mathrm{C} / \mathrm{m}^{2}$ after separation. Oscilloscopic observations of discharges in the approaching procedure revealed that charge is lost through a large number of regular Trichel pulses in the negative corona, while in the positive corona, charge is lost through pulseless glow when fine electrodes are applied; the glow gives way to large pulses as the diameter of the electrode increases. While the amount of lost charge agreed well with the total charge of the pulses and pulseless glow observed by oscilloscope in the approaching procedure, these charges did not agree in the separation procedure. This disagreement was ascribed to the small ratio of the stray capacity to the capacity between the cloth and the backing plate. However, discharges in the separation procedure were found to be similar to those in the approaching procedure by analysing the charge distribution patterns.

KEY WORDS Static Electricity / Cloth / Charge Density / Corona

Discharge / Pulse / Glow /
\end{abstract}

Static electrification of insulators can cause various troubles and hazards, such as electrical shocks and even explosions of combustible mixtures. To avoid these ploblems, different studies have been made especially with regard to ignition capability by discharges from insulators. ${ }^{1,2}$ The basic characteristics of these discharges, however, have not yet been made clear.

In this paper, a new system to investigate the overall characteristics of discharges from insulators is proposed and applied to cloths made of natural and synthetic fibers. This system involves measuring a generated charge, electrifying cloths with good reproducibility, selecting the appropriate $R C$ time constant in the oscilloscopic observations, and checking the results of such observations.

Although the charging and discharging procedures of insulators are complicated, they usually follow one of three procedures: generation of charge by contact or friction, charge

* Present address: Fiber \& Textile Research Institute, Teijin Limited, Ibaraki, Osaka. dissipation in the course of peeling off, or charge dissipation in the course of approaching grounded materials. Investigations will be made separately in the case of charging, separating, and approaching procedures.

\section{EXPERIMENTAL}

Woven cloths were used as test cloths, and knit cloths as rubbing cloths and under-cloths. Materials of the cloths used in the experiment are listed in Table I. Each cloth was washed, dried, and conditioned at $22^{\circ} \mathrm{C}$ and $30-\%$ relative humidity for at least $24 \mathrm{hr}$ before experimentation.

A test cloth was put on an under-cloth and was charged by friction with a rubbing cloth composed of the same material as the undercloth (Figure 1a). A metallic plate was placed in close contact with the test cloth and brought up together with the test cloth using two-sided adhesive tape. The charge induced on the metallic plate was measured by a Takeda Riken Type TR-84M Vibrating Reed Electrometer 
Table I. Materials of the cloths used in the experiment

Test choths (Woven, $22 \mathrm{~cm} \times 31 \mathrm{~cm}$ )

1. Polyester/rayon, $65 / 35$

2. Poly(vinyl alcohol)

3. Poly(vinyl alcohol)/cotton, 50/50

4. Cotton

5. Polyester/cotton, $65 / 35$

7. Polyacrylonitrile

Rubbing and under-cloths (Knit)
a. Wool
b. Cotton
c. Polyacrylonitrile
d. Poly(vinyl chrolide)

(a)
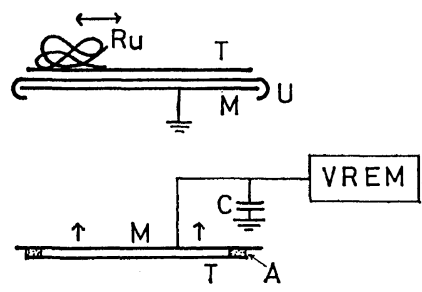

(b)

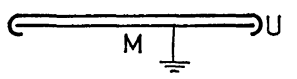

(c)

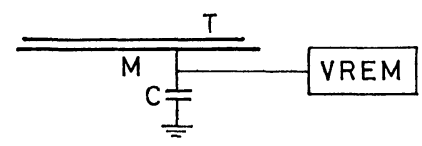

(d)

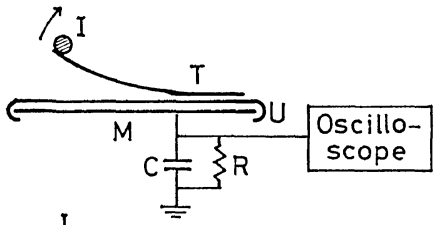

(e)

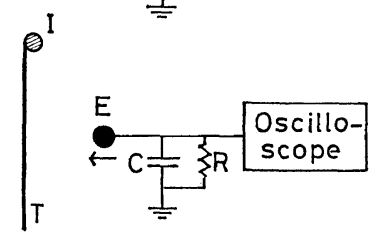

Figure 1. Schematic diagrams of the experiments: (a) electrification by rubbing; (b) measurement of generated charge, $G_{\mathrm{G}}$; (c) measurement of residual charge, $q_{\mathrm{R}}$ and $q_{\mathrm{R}}{ }^{\prime}$; (d) observation of discharges in the separation procedure; (e) observation of discharges in the approaching procedure; $\mathrm{T}$, test cloth; $\mathrm{Ru}$, rubbing cloth; $\mathrm{U}$, under-cloth; $\mathrm{R}$, resistor; $\mathrm{A}$, two-sided adhesive tape; I, insulating rod; E, sphere or wire electrode.
(VREM) (Figure 1b). Since the outer electric field of the test cloth is kept almost zero due to the lower or upper metallic plate, or both, throughout the course of this test, it is suspected that no discharge can occur in this procedure and that the induced charge is equivalent to the charge on the test cloth in the final stage. Hence, the induced charge can be deemed equivalent to the charge on the test cloth generated by rubbing, $q_{G}$.

In another experiment, the charged test cloth was peeled away from the under-cloth; the accompaning discharges were observed by a Matsushita Communication Works Type VP548B $100 \mathrm{MHz}$ Oscilloscope (Figure 1d).

The residual charge, $q_{\mathrm{R}}$, after separation, was measured by the quasi-Faraday cylinder method, in which the charged test cloth was put on a floated metallic plate connected with the VREM (Figure 1c). Preliminary experiments proved this method to be more reproducible than the conventional Faraday cylinder method for measuring charge of this layers. $q_{\mathrm{G}}$ and $q_{\mathrm{R}}$ were divided by the area of the test cloth to give the generated charge density, $Q_{\mathrm{G}}$, and the residual charge density, $Q_{\mathrm{R}}$.

The last experiment was to cause metallic spheres of diameters from 3 to $40 \mathrm{~mm}$ or metallic wires with diameters from $50 \mu$ to 1 $\mathrm{mm}$ to approach at a constant speed of $34 \mathrm{~cm} / \mathrm{sec}$ (Figure 1e). The wire was set perpendicular to the cloth to form the point-to-plane configuration. The discharges in this procedure were also observed by the oscilloscope. In the oscilloscopic observations, the $R C$ time constant was selected as either $9 \times 10^{-10} \mathrm{sec}, 1 \times 10^{-5} \mathrm{sec}$, or $2 \times 10^{-1} \mathrm{sec}$.

The residual charge after the approaching procedure was over, $q_{\mathrm{R}}{ }^{\prime}$, was also measured by the quasi-Faraday cylinder method.

To check the results of these oscilloscopic observations, the total charge observed by the oscilloscope was compared with either the lost charge in the separating procedure, $q_{\mathrm{L}}=q_{\mathrm{G}}-q_{\mathrm{R}}$, or that in the approaching procedure, $q_{\mathrm{L}}{ }^{\prime}=q_{\mathrm{R}}-q_{\mathrm{R}}{ }^{\prime}$.

\section{RESULTS AND DISCUSSION}

\section{Charge Density}

The generated charge density, $Q_{\mathrm{G}}$, of test 
cloths charged by rubbing with four kinds of rubbing cloths is shown in Figure 2. The values of $Q_{\mathrm{G}}$ were distributed up to $45 \mu \mathrm{C} / \mathrm{m}^{2}$, and the order of $Q_{\mathrm{G}}$ agreed well with the conventional triboelectric series. ${ }^{3}$

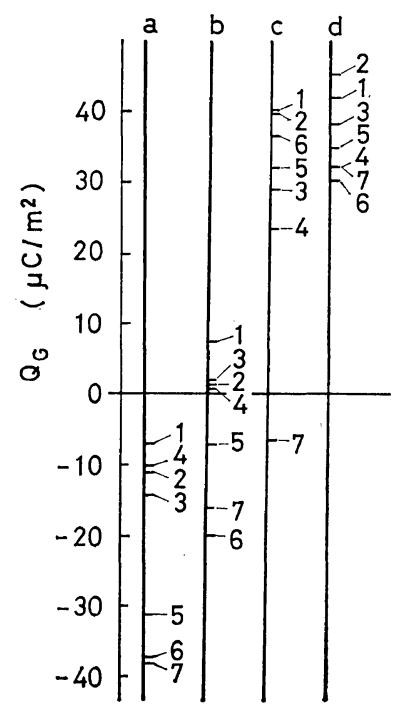

Figure 2. Generated charge density of test cloth, $Q_{G}$, for each rubbing cloth. Figures and symbols denote the materials of the cloths indicated in Table I.

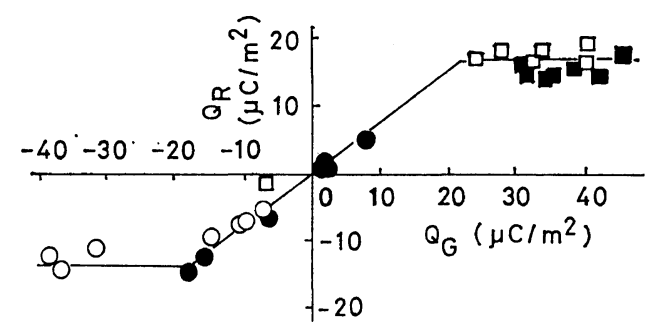

Figure 3. Residual charge density, $Q_{\mathrm{R}}$, plotted against generated charge density, $Q_{\mathrm{G}}$ : rubbing cloth with $\bigcirc$, wool; $\bullet$, cotton; $\square$, polyacrylonitrile; $\boldsymbol{\square}$, poly(vinyl chrolide).
In Figure 3, the residual charge density, $Q_{\mathrm{R}}$, measured after separation, is plotted against $Q_{\mathrm{G}}$. $\quad Q_{\mathrm{R}}$ increases concurrently with $Q_{\mathrm{G}}$ and levels off at about $15 \mu \mathrm{C} / \mathrm{m}^{2}$. This confirms the fact $^{4}$ that the maximum charge density of a thin insulating layer is approximately one half of that of a thin conducting layer calculated from the breakdown field in the air, or $(1 / 2) \times 2.7 \times$ $10^{-5} \mathrm{C} / \mathrm{m}^{2}$. Moreover, Figure 3 shows that thin layers can be charged with good reproducibility by rubbing with some kind of other material and then peeling off. Polyester cloth, for example, can be built up to the maximum charge density positively by rubbing with a poly(vinyl chloride) cloth and negatively by rubbing with a wool cloth.

The difference of the generated charge, $q_{G}$, and the residual charge, $q_{\mathrm{R}}, q_{\mathrm{L}}=q_{\mathrm{G}}-q_{\mathrm{R}}$, is supposed to be lost through discharges to the backing plate in the course of separation.

The charge lost through discharges to approaching electrodes, $q_{\mathrm{L}}{ }^{\prime}=q_{\mathrm{R}}-q_{\mathrm{R}}{ }^{\prime}$, was also evaluated by measuring the residual charge, $q_{\mathrm{R}}{ }^{\prime}$, after the approaching procedure was over. Examples of $q_{\mathrm{L}}$ and $q_{\mathrm{L}}{ }^{\prime}$ are listed in Table II.

Since a large proportion of charge is lost during both the separating and the approaching procedures, it becomes indispensable to scrutinize discharges in both procedures. In the following sections, oscilloscopic observations will be reported for discharged in both procedures.

Discharges in the Approaching Procedure

A polyester test cloth was built up either positively or negatively to the maximum charge density by rubbing with either a poly(vinyl chloride) cloth or a wool cloth and then peeling off the under-cloth. Electrodes were brought close to the built-up cloths and the oscilloscopic waveforms were observed.

To find out the general characteristics of the discharges, a large $R C$ time constant, $R C=$

Table II. Examples of $q_{\mathrm{L}}$ and $q_{\mathrm{L}}{ }^{\prime}$

\begin{tabular}{|c|c|c|c|c|c|c|}
\hline Test cloth & $\begin{array}{c}\text { Rubbing \& } \\
\text { under-cloths }\end{array}$ & $\begin{array}{c}q_{\mathrm{G}} \\
10^{-7} \mathrm{C}\end{array}$ & $\begin{array}{c}q_{\mathrm{R}} \\
10^{-7} \mathrm{C}\end{array}$ & $\begin{array}{c}q_{\mathrm{R}^{\prime}, \mathrm{a}} \\
10^{-7} \mathrm{C}\end{array}$ & $\begin{array}{c}q_{\mathrm{L}} \\
10^{-7} \mathrm{C}\end{array}$ & $\begin{array}{c}q_{\mathrm{L}^{\prime}, \mathrm{a}} \\
10^{-7} \mathrm{C}\end{array}$ \\
\hline \multirow[t]{2}{*}{ Polyester } & Wool & -22.0 & -7.6 & -0.4 & -14.4 & -7.2 \\
\hline & Poly(vinyl chloride) & 26.0 & 9.3 & 0.9 & 16.7 & 8.4 \\
\hline
\end{tabular}

a $q_{\mathrm{R}}{ }^{\prime}$ and $q_{\mathrm{L}}^{\prime}$ for the electrode with a diameter of $1 \mathrm{~mm}$ are listed. 


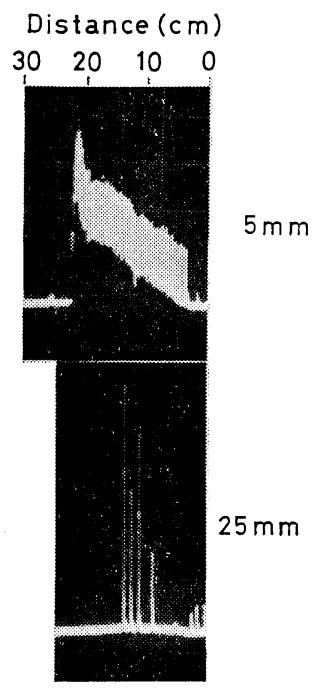

(a)

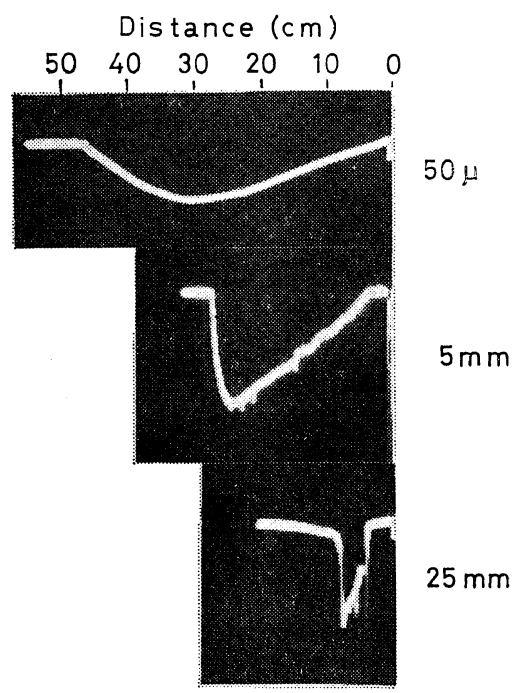

(b)

Figure 4. Discharges in the approaching procedure for the electrodes with diameters of $50 \mu, 5 \mathrm{~mm}$, and $25 \mathrm{~mm} ; R C, 2 \times 10^{-1} \mathrm{sec}$. (a) negative corona, $5 \mathrm{~mm}, 0.5 \mathrm{~V} / \mathrm{div} ; 25 \mathrm{~mm}, 2 \mathrm{~V} / \mathrm{div}$. (b) positive corona, $0.5 \mathrm{~V} / \mathrm{div}$ each.

$2 \times 10^{-1} \mathrm{sec}$, was employed. Figure 4 shows the results for various diameters of electrodes and for both polarities of cloths. In the negative corona, where cloths were charged positively, a number of very regular Trichel pulses broke in upon the oscillograph and lasted until the electrodes came close to the test cloth. The number of pulses decreased as the diameter increased, and in electrodes with diameters larger than $10 \mathrm{~mm}$, a large pulse was followed by a few smaller pulses. In the positive corona, in contrast, a pulseless glow discharge was dominant with small diameters, which, as the diameter increased, gave way to a few irregular pulses larger than those observed in the negative corona.

The difference of positive and negative corona is more explicitly represented in Figure 5, where pulse and glow-discharge regions are illustrated.

Charge transferred from the test cloth to the electrodes was obtained by integrating the current of the pulse or glow discharges. When integrating the pulse current, the $R C$ time constant was selected as $1 \times 10^{-5} \mathrm{sec}$ to avoid superposition of adjacent pulses. Figure 6 shows the pulse charge for positive and negative coronas. ${ }^{5}$

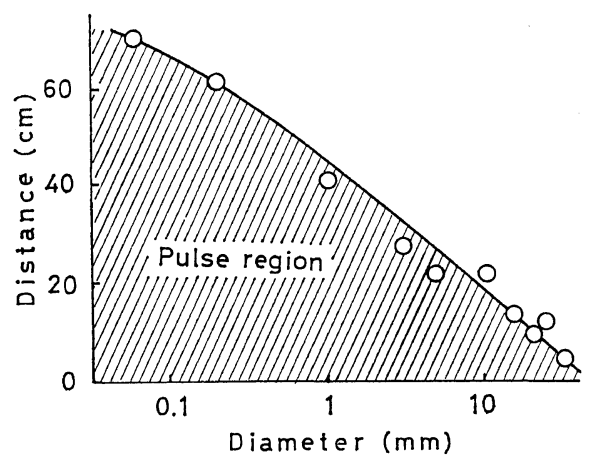

(a)

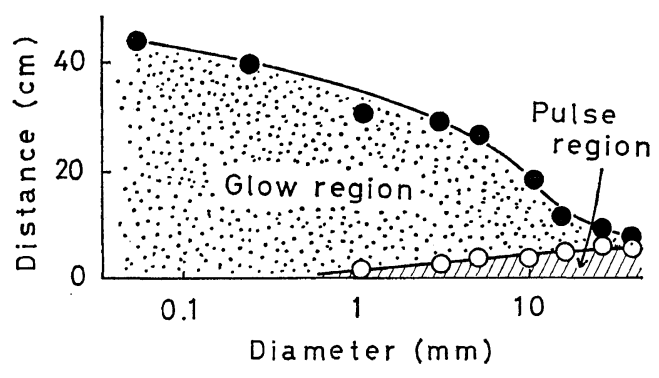

(b)

Figure 5. Sequence of events in the approaching procedure: (a) negative corona; (b) positive corona. $O$ denotes the distance at which pulse discharges commence and denotes the distance at which glow discharge commences. 


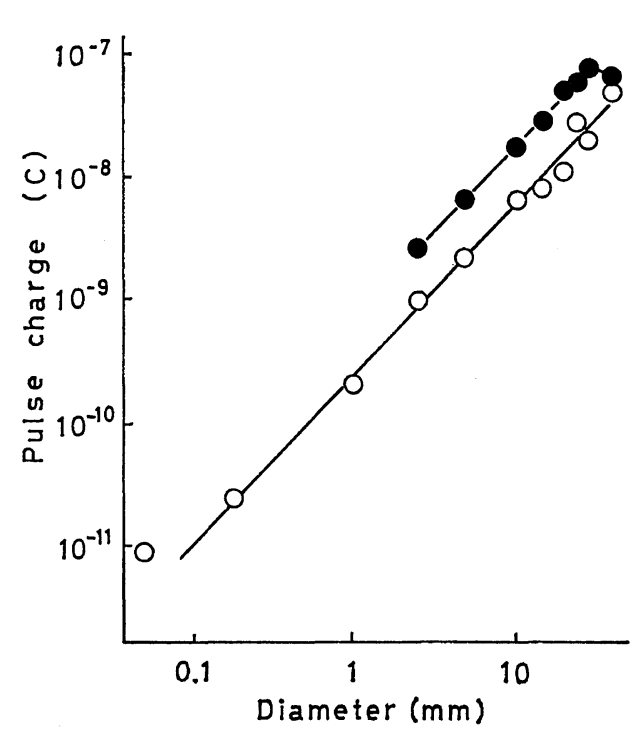

Figure 6. Single pulse charge plotted against diameter of electrode: $\bigcirc$, negative corona; positive corona.

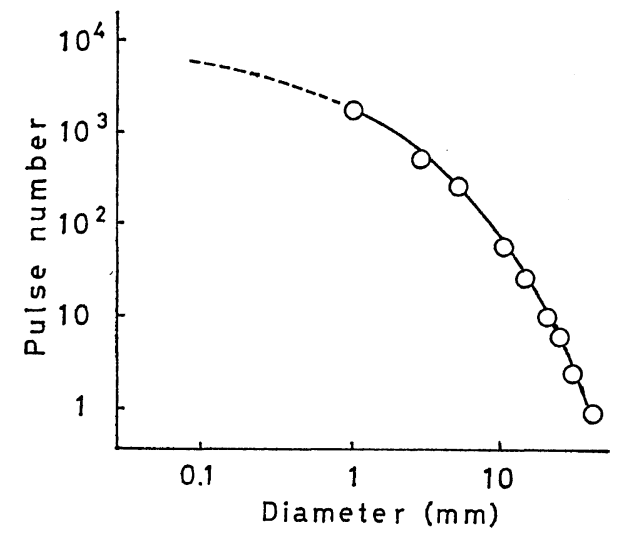

Figure 7. Pulse number plotted against diameter of electrode, negative corona.

In case the pulses were irregular and sporadic, the maximum pulse charge was plotted in Figure 6. The pulse charge increases progressively with the electrode diameter. The pulse charge was larger in the positive corona than in the negative corona with the same electrode diameter.

These results are consistent with the experimental results ${ }^{2,4}$ that the relative frequency of ignition of combustible mixture by discharges from insulators increases with increasing elec- trode diameter and that the negatively charged insulators have a higher frequency of ignition than positively charged ones.

All the pulse charges observed by the oscilloscope during the approach of electrodes were summed up to give the total lost charge through the pulse discharge, $q_{\text {pulse }}$. When the pulses were regular and frequent, the pulse number was counted by a Takeda Riken TR-5410 Electronic Counter (Figure 7), and multiplied by the charge of a single pulse. The charge lost through the glow discharge, $q_{\text {glow }}$, was also obtained by integrating the traces in Figure $4 \mathrm{~b}$. In Figure $8, q_{\text {pulse }}$ and $q_{\text {glow }}$ are compared with

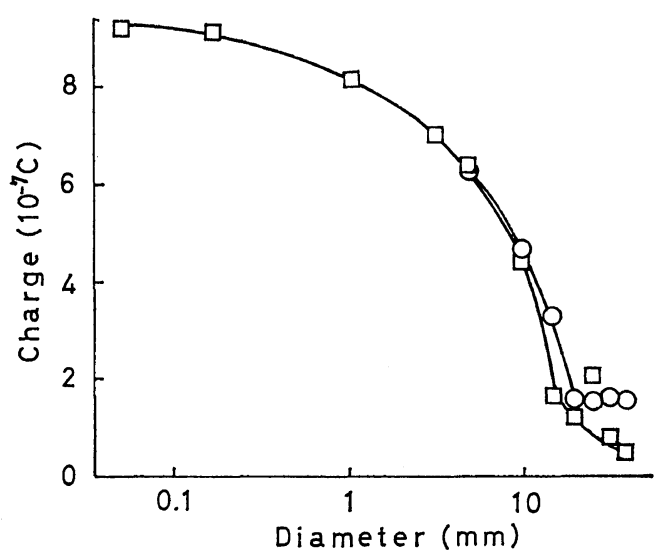

(a)

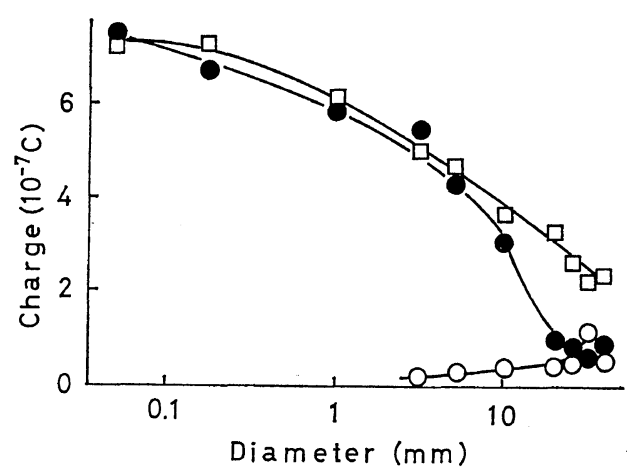

(b)

Figure 8. Comparison of the lost charge, $q_{\mathrm{L}}{ }^{\prime}$, observed by the quasi-Faraday cylinder method, and the lost charge observed by the oscilloscope: (a) negative corana; (b) positive corona. $\square, q_{\mathrm{L}}{ }^{\prime} ; \bigcirc$, lost charge through the pulse discharges; $\bigcirc$, lost charge through the glow discharge. 


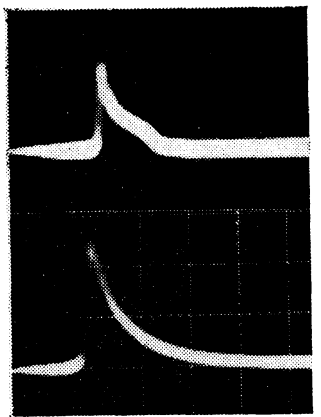

(a)

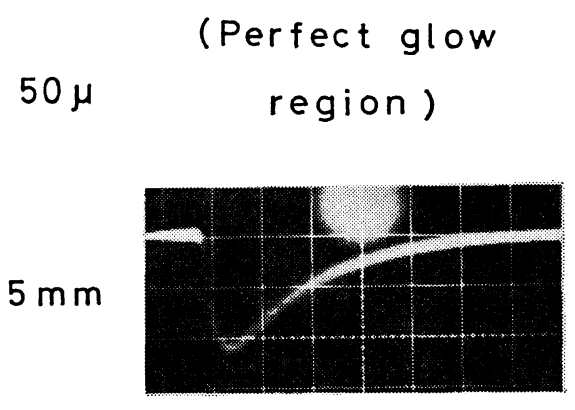

(b)

Figure 9. Pulse waveforms in the approaching procedure for the electrodes with diameters of $50 \mu$ and $5 \mathrm{~mm} ; R C, 9 \times 10^{-10} \mathrm{sec}$. Some ten pulses were superposed to give the traces shown. Horizontal, $50 \mathrm{nsec} / \mathrm{div}$. (a) negative corona, $50 \mu, 5 \mathrm{mV} / \mathrm{div} ; 5 \mathrm{~mm}, 0.1 \mathrm{~V} /$ div. (b) positive corana, $5 \mathrm{~mm}, 1 \mathrm{~V} / \mathrm{div}$.

$q_{\mathrm{L}}{ }^{\prime}$. The lost charge observed by the oscilloscope agrees well with $q_{\mathrm{L}}{ }^{\prime}$. Thus, the oscilloscopic observations made in the approaching procedure have beed confirmed as reliable.

The current waveforms of discharges were observed using a circuit with a small $R C$ time constant, $R C=9 \times 10^{-10} \mathrm{sec}$. Here, the signal was sent through a terminated $50-\mathrm{ohm}$ coaxial cable and the entire observing system, including the test pieces, was shielded.

The observed traces are shown in Figure 9. In the negative corona, a sharp kick was followed by a plateau, ${ }^{5}$ while in the positive corona, an initial slow rise $^{6}$ was observed.

\section{Discharges in the Separation Procedure}

Discharge pulses in the separation procedure were also observed by the oscilloscope (Figure 1d).

In Table III, the total pulse charge, $q_{\text {pulse }}$, observed in the course of separation is compared with $q_{\mathrm{L}}$. $q_{\text {pulse }}$ was only one-hundredth of $q_{\mathrm{L}}$. This disagreement may be partially ascribable to a glow discharge current that cannot be observed due to an inductive current from the charge of the test cloth. But the main reason for this disagreement seems to be a small ratio of the stray capacity, $C_{1}$, to the capacity between the cloth and the backing plate, $C_{2}$.

An equivalent network for a discharge from the cloth is given in Figure 10, where the discharges to the metallic plate or the electrodes are equivalent to closing the switch, $\mathrm{Sw}$. In
Table III. Comparison between the lost charge, $q_{\mathrm{L}}$, and the total pulse charge observed by oscilloscope, $q_{\text {pulse }}$, in the course of separation ${ }^{a}$

\begin{tabular}{lcr}
\hline \multicolumn{1}{c}{ Test cloth } & $\begin{array}{c}q_{\mathrm{L}}{ }^{\prime}, \\
10^{-7} \mathrm{C}\end{array}$ & $\begin{array}{r}q_{\text {pulse }}, \\
10^{-9} \mathrm{C}\end{array}$ \\
\hline Polyester/rayon & 17.2 & 11.5 \\
Poly(vinyl alcohol) & 14.4 & 5.4 \\
Poly(vinyl alcohol)/cotton & 14.2 & 11.0 \\
Cotton & 12.3 & 11.7 \\
Polyester/cotton & 11.3 & 10.7 \\
Polyester & 16.7 & 10.3 \\
Polyacrylonitrile & 11.5 & 4.5 \\
\hline
\end{tabular}

a As rubbing and under-cloths, poly(vinyl chrolide) cloths were used.

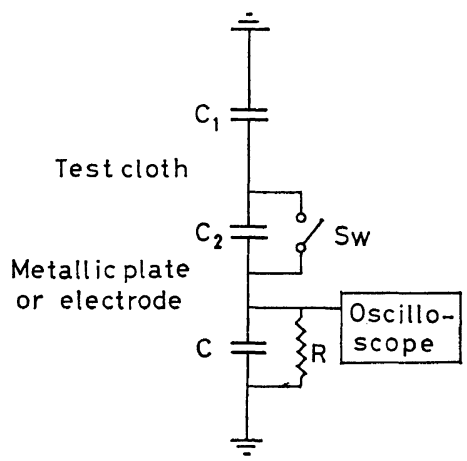

Figure 10. An equivalent network for the observation system of discharges. Discharges are equivalent to closing the switch, Sw. 
Figure 10, the charge observed by the oscilloscope can be given as

$$
Q_{\mathrm{obsd}}=\frac{C_{1}}{C_{1}+C_{2}} Q_{\text {lost }}
$$

where $Q_{\text {lost }}$ is the charge actually lost by a discharge. In case $C_{2} \gg C_{1}$, where

$$
Q_{\text {obsd }} \cong \frac{C_{1}}{C_{2}} Q_{\text {lost }}
$$

only a small proportion of lost charge can be observed by the oscilloscope.

In reality, such discharges occur a number of times in the separation and approaching procedures, and $C_{1} / C_{2}$ varies from time to time and from place to place. It is therefore difficult to obtain the effective value of $C_{1} / C_{2}$.

However, $C_{1} / C_{2}$ for a stationary cloth may be obtained by measuring the induced charge on the floated metallic plate or sphere and calculating with the equation

$$
\frac{C_{1}}{C_{2}}=\frac{q}{q_{C_{2}}}-1
$$

where $q$ is the charge on the cloth and $q_{C_{2}}$ is the induced charge on the metallic plate or sphere.

In Figure $11, C_{1} / C_{2}$ is plotted against distance. Here, the cloth was charged slightly to avoid discharging. Since $C_{1} / C_{2}$ is very small for the plate at small distances, it is suspected that the

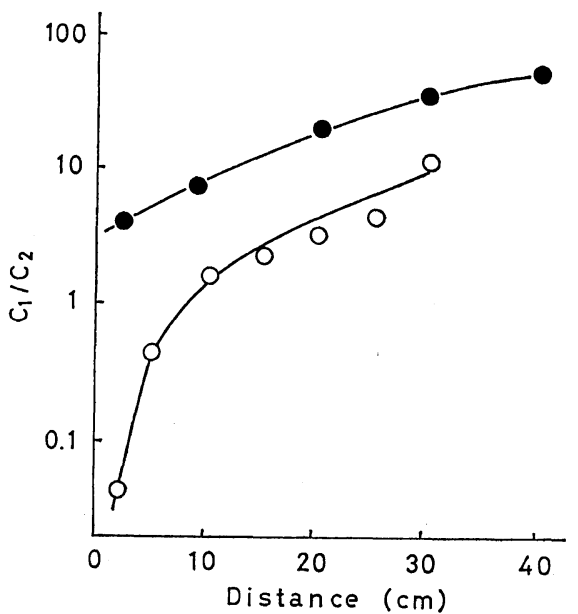

Figure 11. $C_{1} / C_{2}$ plotted against distance between the test cloth and $\bigcirc$, the metallic plate, or $\bigcirc$, the sphere electrode with a diameter of $10 \mathrm{~mm}$. effective value of $C_{1} / C_{2}$ in the separation procedure is very small, thus accounting for the disagreement of $q_{\text {pulse }}$ and $q_{\mathrm{L}}$.

Thus, the observed pulses in the separation procedure proved to be of low reliability. To clarify the characteristics of the discharges in this procedure, the following experiment was resorted to.

A polycarbonate film was charged electrically with the use of needles which were put on a grounded metallic roller and connected to a high-voltage source. The film was run at a speed of $5 \mathrm{~m} / \mathrm{min}$. The film was powdered with quartz after being removed from the roller.

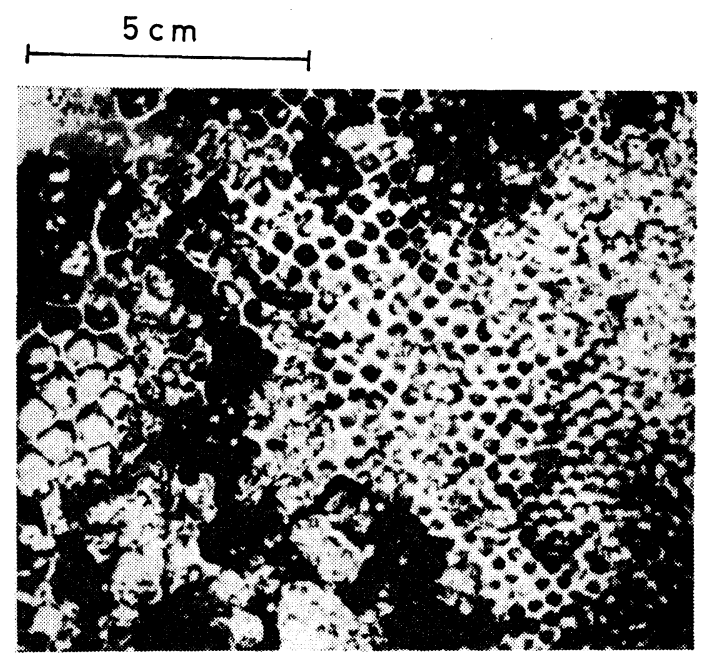

(a)

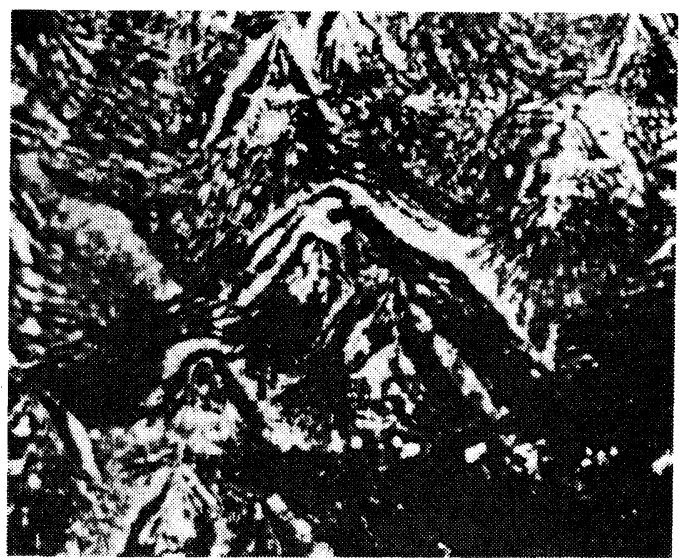

(b)

Figure 12. Charge distribution patterns: (a) positively charged film; (b) negatively charged film. 


\section{T. Hirakawa}

In Figure 12, the charge-distribution patterns obtained by this method are shown. While in the negatively charged film, large branched patterns $^{7}$ appeared, a large number of regular, hexagonal or pentagonal patterns appeared in the positively charged film. Although this experiment was made only for the polycarbonate film, these patterns seem to reflect the general characteristics of discharges in the separation procedure. Here, as in the approaching procedure, it is suspected that the pulses are regular and frequent in positively charged cloths, and that they are irregular and sporadic in negatively charged cloths.

\section{Specific Nature of Discharges from Insulators}

The pulsating nature of the negative corona can be accounted for by the cessation of ionization due to the accumulation of negative ions just outside the positive space charge, ${ }^{8}$ and the dominant pulseless glow in the positive corona is a result of the Hermstein negative ion sheath. ${ }^{9}$ The fast rise of the current waveform in the negative corona, the sharp section shown in Figure 9a, is evidence of effective photoelectric emission in which the sphere or wire electrodes play an important role. ${ }^{10}$

All these phenomena are replicas of discharges between metals, with the exception that in the approaching procedure, the pulse corona follows the glow in the positive corona. Hermstein ${ }^{11}$ determined the sequence of events in the pointto-plane configurations and later Vuhuu, et al., ${ }^{12}$ determined it in the wire-to-plane configurations. Their results suggest that, in bringing grounded electrodes near to negatively charged materials, the pulse corona is followed by the glow corona which continues until at last a spark ensues. Likewise, in the case of positively charged materials, a spark follows the pulse corona. In cloths, however, as in plastic films, ${ }^{13}$ the visual appearance of the pulse discharges indicated that all the pulse discharges were not sparks: the blue streak branched and faded away on the way in the negative corona, and one or several bright spots were confined to the high field region in the positive corona.

\section{CONCLUSIONS}

1. Reproducible charging of a cloth may be attained by rubbing it with a cloth quite different in triboelectric properties and peeling it off.

2. Discharges from insulators form a sharp contrast in the negative and the positive corona. They mainly consisted of regular Trichel pulses in the negative corona, and a pulseless glow or large pulses in the positive corona. Pulse and glow discharges can be observed by employing appropriate $R C$ time constants.

3. In investigating discarges from insulators by oscilloscopes, it is to be noted that only a loss of the charge which was stored in the stray capacitor can be observed. In the separating procedure, the stray capacity is far smaller than the capacity between the cloth and the backing plate, which causes an unobservable lost charge. It is thus indispensable to check the results of oscilloscopic observations by comparing them with the lost charge measured by other means.

Acknowledgement. The author wishes to express his gratitude to Prof. Z. Ohtaki of Sophia University and Mr. Y. Tabata of the Research Institute of Industrial Safety, Ministry of Labor, for their continuing and cordial guidance.

\section{REFERENCES}

1. N. Gibson and F. C. Lloyd, Brit. J. App. Phys., 16, 1619 (1965).

2. E. Heiderberg, Proc. 2nd Conf. Static Electrification, Ins. Phys. Ser., No. 4, p 3, (1967).

3. W. R. Herper, "Contact and Frictional Electrification," Oxford University Press, 1967, p 352.

4. E. Heiderberg, IEE Con. Pub., 75, 68 (1971).

5. M. R. Amin, J. Appl. Phys., 25, 627 (1954).

6. M. R. Amin, ibid., 25, 358 (1954).

7. H. Bertein, Proc. 2nd Conf. Static Electrification, Ins. Phys. Ser., No. 4, p 11 (1967).

8. L. B. Loeb, "Electrical Coronas," University of California Press, 1965, p 310.

9. L. B. Loeb, ibid., p 38.

10. L. B. Loeb, ibid., p 344.

11. W. Hermstein, Archiv für Electrotech., 45, 209 (1960).

12. Q. Vuhuu and R.P. Cosma, IEEE Trans. Power App. Syst., PAS-88, 1462 (1969).

13. Y. Tabata, Abstracts, 18th Conf. of Electrostatic Society of Japan, Tokyo, July 5-6, 1973, p 55. 